\title{
Characterization of Cells of Amniotic Fluids by Immunological Identification of Intermediate-Sized Filaments: Presence of Cells of Different Tissue Origin
}

\author{
M. Cremer ${ }^{1}$, I. Treiss ${ }^{1}$, T. Cremer ${ }^{1}$, D. Hager ${ }^{1}$, and W. W. Franke ${ }^{2}$ \\ ${ }^{1}$ Institut für Anthropologie und Humangenetik, Universität Heidelberg, Im Neuenheimer Feld 328, 6900 Heidelberg \\ ${ }^{2}$ Abteilung für Membranbiologie und Biochemie, Institut für Zell- und Tumorbiologie, Deutsches Krebsforschungszentrum, 6900 Heidelberg, \\ Federal Republic of Germany
}

Summary. Antibodies against intermediate-sized filaments, of the prekeratin or vimentin type, were used to investigate the presence of these filaments by indirect immunofluorescence microscopy in cultured and non-cultured amniotic fluid cells, in frozen sections of the placenta and in isolated cells of the amniotic epithelium. Two major classes of cells can be cultured from amniotic fluids, namely cells of epithelial origin containing filaments of the prekeratin type and cells of different origin which contain filaments of the vimentin type but are negative when tested with antibodies to epidermal prekeratin. The presence of prekeratin type filaments correlates with the morphology of colonies of amniotic fluid cell cultures in vitro as classified by Hoehn et al. (1974). Cells of E-type colonies are shown to be of epithelial origin. In contrast our data indicate a different origin of almost all cells of F-type colonies and of the large majority of cells of AF-type colonies. Cells of epithelial origin and positively stained with antibodies to epidermal prekeratin are occasionally scattered in F-type colonies and in variable percentages (up to $30 \%$ ) in AF-type colonies. Surprisingly, cryostat sections of the amniotic epithelium and isolated groups of amniotic cells showed positive reactions with both antibodies to vimentin and prekeratin. The possibility that amniotic cells may be different from other epithelial cells in that they contain both types of filaments simultaneously already in situ is presently under investigation.

\section{Introduction}

Cultured cells from amniotic fluid of midtrimester pregnancies are in widespread use for the prenatal diagnosis of genetic disorders of the fetus. The morphologic heterogeneity of these cells is well known and morphologic criteria have been used, in addition to biochemical ones, for their characterization (Melancon et al. 1971; Gerbie et al. 1972; Macek et al. 1973; Hoehn et al. 1974; Priest et al. 1977; Crouch and Bornstein 1979; Tyden et al. 1981). Hoehn et al. (1974) described three types of colonies corresponding to their morphology and growth

Offprint requests to: $\mathrm{M}$. Cremer

* Part of this work is included in the doctoral thesis of Irmgard Treiss to be submitted to the Faculty of Medicine of the University of Heidelberg potential: (1) E-type colonies consisting of epithelioid cells with intimate cell-to-cell contacts and relatively poor growth potential. (2) F-type colonies with a high growth potential composed of spindle-shaped cells growing in parallel arrays and morphologically indistinguishable from fetal fibroblasts. (3) AF-type colonies representing an intermediate type, composed of so called amniotic fluid cells (AF-cells) of pleomorphic appearance (i.e., of fibroblastoid or epithelial shape) but without intimate cell-to-cell contacts. The latter type of cell colonies is predominant in cultures of amniotic fluid cells.

Clonable amniotic fluid cells may be derived either from the fetus or from the cytotrophoblast. All epithelial surface cells that are in direct or indirect contact with the amniotic fluid have been considered as the sources of such cells including fetal epidermis, the epithelial cells of the respiratory, the urinary, and the intestinal tract of the fetus, and the epithelium of the "amniotic membrane" (Gerbie et al, 1972; Hoehn et al. 1975). The occurrence of cells with fibroblast-like morphology and detection of collagen type I in these cultures suggest that some of the clonable cells are true fibroblasts which stem from the connective tissue underlying the epithelial layers mentioned above (Macek et al. 1973; Priest et al. 1977; Hurych et al. 1976).

A new approach to identify the origin of single amniotic fluid cells has been made possible by the recent detection that the specific patterns of intermediate-sized filaments differ in different cell types formed during embryogenesis (Jackson et al. 1980 to be published; Schnitzer et al. 1981). For example it has been shown (Aula et al. 1980; Cremer et al. 1981) that cells of glial origin are often present in amniotic fluids of pregnancies with neural tube defects but not in normal pregnancies. This was demonstrated by the immunologic identification of glial fibrillary acidic protein which constitutes a type of intermediate-sized filament specific for glial cells. Further evaluation of such differences between normal and pathologic pregnancies makes it necessary to characterize the spectrum of cell types in normal amniotic fluids.

In the present study it was our aim to investigate the epithelial or mesenchymal origin of amniotic fluid cells in normal pregnancies of 35-40 year-old women who received prenatal chromosome diagnosis because of their increased risk to bear a fetus with a numerical chromosome aberration. For our purpose we used antibodies against intermediate-sized filaments of the prekeratin and vimentin type. Filaments of the prekeratin type are present in most, if not all true epithelial cells in situ (Franke et al. $1978 \mathrm{a}, 1979 \mathrm{a}, \mathrm{b}, 1981 \mathrm{a}, \mathrm{b}$ ) and are also 
formed in a variety of cultured epithelial cells (Franke et al. 1978 b, 1979 c) but do not occur in mesenchymal cells. The demonstration of prekeratin-type filaments can therefore be considered as proof for the epithelial origin of a cell. In cells of mesenchymal origin a different type of intermediate-sized filaments containing a single polypeptide, vimentin, is formed in vivo and in vitro (Franke et al. $1979 \mathrm{~d}$ ). In the tissue vimentin decorates mesenchymal cells and has so far not been shown in true epithelial cells, although certain "epithelioid" cell types such as endothelial and lens forming cells contain filaments of this type (Franke et al. 1979 f; Schmid et al. 1979; Ramaekers et al. 1980; Schnitzer et al. 1981). In vitro, however, expression of vimentin type intermediate-sized filaments is also observed in diverse non-mesenchymal cells such as cells of epithelial, myogenic, or neuronal origin (Franke et al. $1978 \mathrm{a}, 1979 \mathrm{~d}, \mathrm{e}$ ). Immunologic detection of vimentin therefore provides a criterion to characterize mesenchymal cells grown in the tissue but does not provide a positive criterion to identify the origin of cells grown in culture.

To exploit this strategy for the identification of the origin of different cells in amniotic fluids it is necessary to know the filament pattern in situ of all cell types which can possibly contribute to amniotic fluid cells. Prekeratin has been demonstrated in the epidermis and in epithelial cells of the respiratory, intestinal, and urinary tract of mammals and other vertebrates (Franke et al. 1979a, b). All these epithelia have been shown to be negative for vimentin (Franke et al. $1979 \mathrm{~b}$; Schmid et al. 1979). However, a systematic study of the amniotic epithelium is still missing except for a short note that such cells have been found to be prekeratin positive after one week of culturing in vitro (Alitalo et al. 1980). Therefore, we have identified filaments in frozen sections of the placenta, in dissected cells of the amniotic epithelium, in non-cultured amniotic fluid cells, and in colonies obtained after 6 to 28 days of culture.

\section{Materials and Methods}

1. Amniotic fluid was obtained by transabdominal amniocentesis in the 17 th week of pregnancy from a total of 32 women between 35 and 40 years of age. Amniocentesis was carried out because of the increased risk of these women to carry a fetus with a numerical chromosome abnormality. In all cases the karyotype evaluated from cultured amniotic fluid cells was normal. Amniotic fluid samples were centrifuged (Christ centrifuge type UJ1, Osterode, Federal Republic of Germany; $1000 \mathrm{rpm}$ ) for $10 \mathrm{~min}$. The pellet of cells was resuspended in Ham's F10 medium supplemented with $20 \%$ fetal calf serum, streptomycin $(100 \mu \mathrm{g} / \mathrm{ml})$, and penicillin $(100 \mathrm{U} / \mathrm{ml})$. Approximately $10^{4}$ cells were seeded in Leighton tubes with $10 \times 50 \mathrm{~mm}$ coverslips in a volume of $2.5 \mathrm{ml}$ medium at $\mathrm{pH} 7.1$. Leighton tubes were sealed and incubated at $37^{\circ} \mathrm{C}$. Fresh medium was applied after five days of culture and every second day thereafter. Primary cultures were used for indirect immunofluorescence microscopy between days 6 and 28 of culture. For the induction of perinuclear aggregates of intermediate-sized filaments, cell cultures were treated with $10^{-6} M$ colcemid for $24 \mathrm{~h}$ (Franke et al. 1979d).

2. Frozen sections of the amniotic epithelium, the chorionic plate, and chorionic villi were obtained from cube-like pieces of about $0.5 \mathrm{~cm}$ in length cut out from a fresh full-term placenta. The tissue pieces were frozen in isopentane cooled with liquid nitrogen to $-150^{\circ} \mathrm{C}$ for two minutes and then stored at $-70^{\circ} \mathrm{C}$.
Cryostat sections were air-dried overnight, immersed for $10 \mathrm{~min}$ in $-20^{\circ} \mathrm{C}$ acetone, and then processed for indirect immunofluorescence labeling. Preimmunization sera from guinea pigs were used as controls for specifity.

3. Isolated cells of the amniotic epithelium were obtained by gently scraping cellular material from the amniotic side of a fresh placenta with a glass slide. Cells were air-dried overnight and treated with Triton-X as described (Franke et al. 1978 a), prior to immunofluorescence labeling.

4. Preparations of non-cultured amniotic fluid cells were made as follows. Cells on $0.5 \mathrm{ml}$ amniotic fluid (five samples) were centrifuged (1000 rpm for $10 \mathrm{~min}$ ) and resuspended in $0.6 \mathrm{ml}$ phosphate buffered saline (PBS). The cells were then spun onto a glass-slide by using a cytospin centrifuge (Shandon Southern, USA; $600 \mathrm{rpm}$ for $5 \mathrm{~min}$ ) and immediately processed for indirect immunofluorescence microscopy.

5. Vimentin antibodies were raised in guinea pigs against human vimentin purified from cytoskeletons of SV40 transformed human fibroblasts (SV80-cells; Franke et al. 1979d). The preparation of guinea pig antibodies against epidermal prekeratin from bovine muzzle which broadly cross-react with prekeratin-like proteins of different tissues and species has been described (Franke et al. 1981 b).

6. For indirect immunofluorescence microscopy cells grown on cover slips were gently washed with PBS (pH 7.3), fixed in absolute methanol at $-20^{\circ} \mathrm{C}$ for $5 \mathrm{~min}$, and dipped in acetone $\left(-20^{\circ} \mathrm{C}\right)$ several times. After air-drying the cells were washed again in PBS and incubated with the first antibody (diluted $1: 50$ ) for $30 \mathrm{~min}$ at $37^{\circ} \mathrm{C}$. Cells were washed three times in PBS. Fluorescein-isothiocyanate (FITC)-conjugated goat antibodies against guinea pig IgG were used as second antibodies (MilesYeda, Rehovot, Israel) at a dilution of $1: 25$. Cells were incubated for $30 \mathrm{~min}$ at $37^{\circ} \mathrm{C}$, then washed in PBS, and the cover slips were mounted on glass slides. Specimens were observed and photographed using a Zeiss photomicroscope equipped with epifluorescence illumination. Pictures were taken on Plus X-Pan film from Kodak. The procedure for frozen sections was the same but without methanol fixation.

\section{Results}

In frozen sections of the placenta, including the amniotic epithelium, the chorionic plate, and some chorionic villi, we found significant staining of the cytoplasm of amniotic cells both with antibodies to prekeratin and to vimentin (Fig. 1 a, b). Cells within the underlying mesenchymal tissue of the chorionic plate were negative with antibodies against prekeratin but positive for vimentin (Fig. $1 \mathrm{a}, \mathrm{b}$ ). The same result was found for endothelial cells of chorionic blood vessels (Fig. 2a,b). By contrast, the epithelial layer of chorionic villi stained positively with prekeratin but was negative for vimentin (Fig. 2a,b). Groups of cells isolated from the amniotic epithelium showed staining with both antibodies to prekeratin and vimentin, decorating filamentous arrays (Fig. $3 \mathrm{a}, \mathrm{b}$ ).

Cells from five samples of amniotic fluid were directly centrifuged onto glass slides. With immunofluorescence microscopy cytoplasmic staining, sometimes revealing fibrils, was found with antibodies to vimentin (Fig. 4a) as well as with antibodies to prekeratin (Fig. 4 b). Other cells in these preparations did not stain with antibodies to prekeratin and vimentin, respectively. Many cells in amniotic fluids were degenerating and could not exclude trypan blue. A quantitative evaluation of 

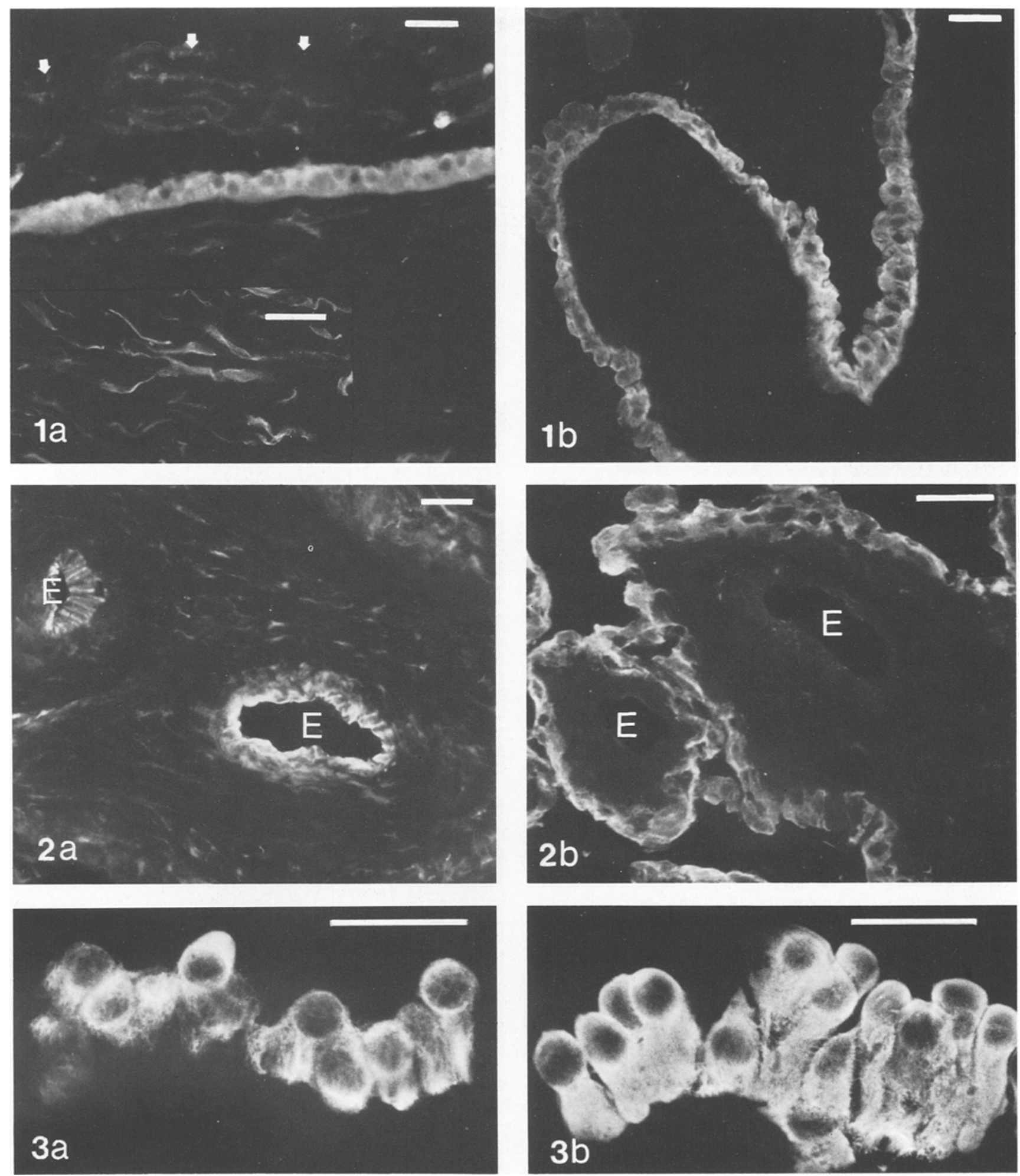

Fig. 1 a and b. Indirect immunofluorescence microscopy on frozen tissue sections of the placenta showing staining of amniotic epithelial cells by antibodies to vimentin (a) and to epidermal prekeratin (b). a The amniotic epithelium is displaced from its original site (indicated by small arrows). Note staining of connective tissue cells scattered in the chorionic plate. The inset in Fig. 1 a shows such cells after a longer exposure. b Cells of the chorionic plate are unstained. Bars, $20 \mu \mathrm{m}$

Fig. 2a and b. Indirect immunofluorescence microscopy of chorionic villi after incubation with antibodies to vimentin (a) and epidermal prekeratin (b). a Endothelial cells of chorionic blood vessels (indicated by E) are strongly decorated. Positive staining is also observed in cells of the vascular wall, while the epithelial layer of the chorionic villi remains unstained. b In contrast to (a). the epithelial layer of the chorionic villi is strongly decorated by antibodies to prekeratin, while staining is absent in the endothelial cells and vascular walls. Bars, $20 \mu \mathrm{m}$

Fig. 3a and b. Indirect immunofluorescence microscopy of isolated groups of the amniotic epithelium. incubated with antibodies to vimentin (a) or epidermal prekeratin (b). The amniotic epithelium is strongly decorated by antibodies to prekeratin. Bars, $30 \mu \mathrm{m}$ 

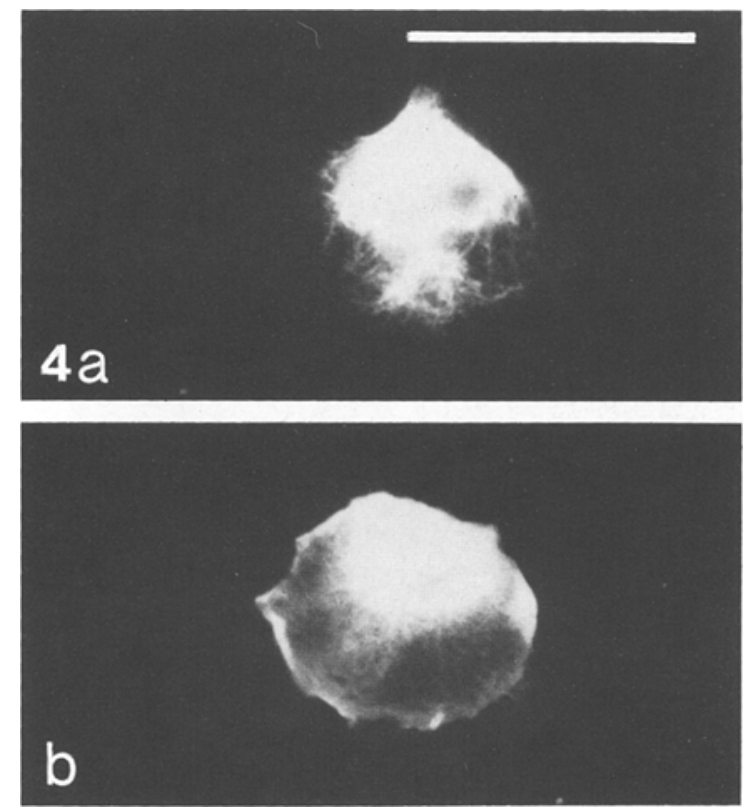

Fig. 4 a and b. Indirect immunofluorescence microscopy of non-cultured amniotic fluid cells after incubation with antibodies to vimentin (a) and prekeratin (b). Positive cells are observed with both antibodies. Bar, $20 \mu \mathrm{m}$

the fraction of cells positive for prekeratin and vimentin in amniotic fluid samples was not tried. The experiments also did not allow the decision whether such cell populations contained cells positive for both vimentin and prekeratin.

We examined a total of 72 cell colonies between days 6 and 28 of culture, originally obtained from the amniotic fluids of a total of 32 women in week 17 or pregnancy. Colonies were classified according to the method of Hoehn et al. (1974) as described above. Small colonies of cells were usually first observed after six to seven days of culture. At that stage E-type colonies could be clearly identified, whereas the unequivocal differentiation between AF-type colonies and F-type colonies was usually feasible only after two weeks of culture. Therefore we classified such colonies before day 14 as AF/F-type colonies.

All cells of 25 colonies (including E-, AF-, and F-type colonies), grown from 14 samples of amniotic fluid and tested between day 6 and 21 of culture, showed positive reaction with vimentin antibodies, displaying typical fibrillar arrays, irrespective of the differences in cell morphology and the time of culturing (Fig. 5a,b). After prolonged treatment ( $24 \mathrm{~h}$ ) of the cultures with $10^{-6} \mathrm{M}$ colcemid, juxtanuclear aggregates showing the characteristic caps and whorls of bundles of vimentin filaments were formed (Fig. 5c; compare Osborn et al. 1977; Bennett et al. 1978; Franke et al. 1978 a, b; Hynes an Destree 1978).

By contrast, when antibodies against epidermal prekeratin were used positive and negative cells could be distinguished. In 20 E-type colonies grown from 14 samples of amniotic fluids and tested between day 6 and day 28 of culture, we found the presence of filaments of the prekeratin type in all cells (Fig. 6). Bundles of filaments of the prekeratin type extended throughout the whole cytoplasm, often showing desmosome-tonofibril complexes (Fig. 6, arrows). After treatment with $10^{-6} M$ colcemid for $24 \mathrm{~h}$ the extended meshwork of filaments of this type was maintained. On the other hand, all 27 non-E-type colonies contained variable fractions of cells negative for epidermal
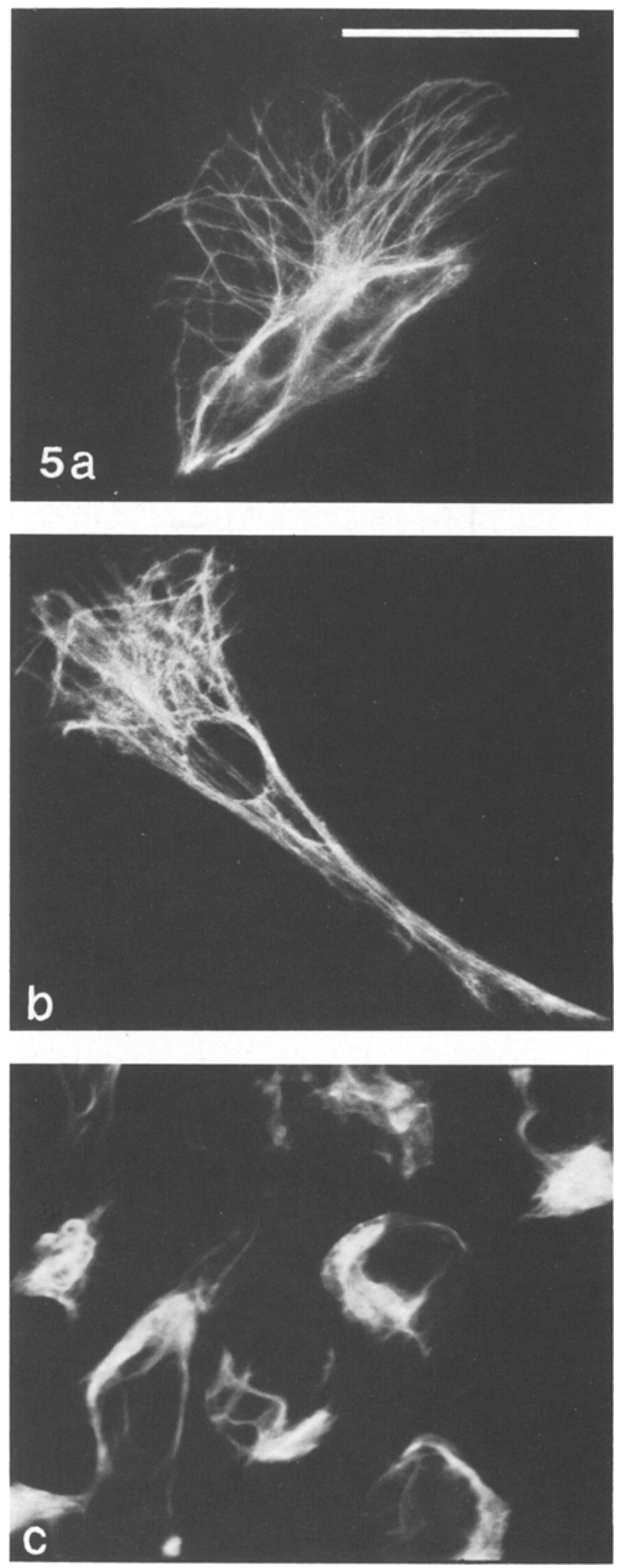

Fig. 5a-c. Indirect immunofluorescence microscopy showing reaction of antibodies to vimentin on (a) an epithelioid. (b) a fibroblastoid cell after seven days of cultivation. Both cells exhibit the typical display of vimentin-containing fibrils, which (c) form juxtanuclear aggregates upon incubation with colcemid. Bar, $20 \mu \mathrm{m}$

prekeratin. This was found in $11 \mathrm{AF} / \mathrm{F}$-type colonies grown from seven samples of amniotic fluid, in six AF-type colonies grown from two samples of amniotic fluid, and in 10 F-type colonies grown from five samples of amniotic fluid. The 


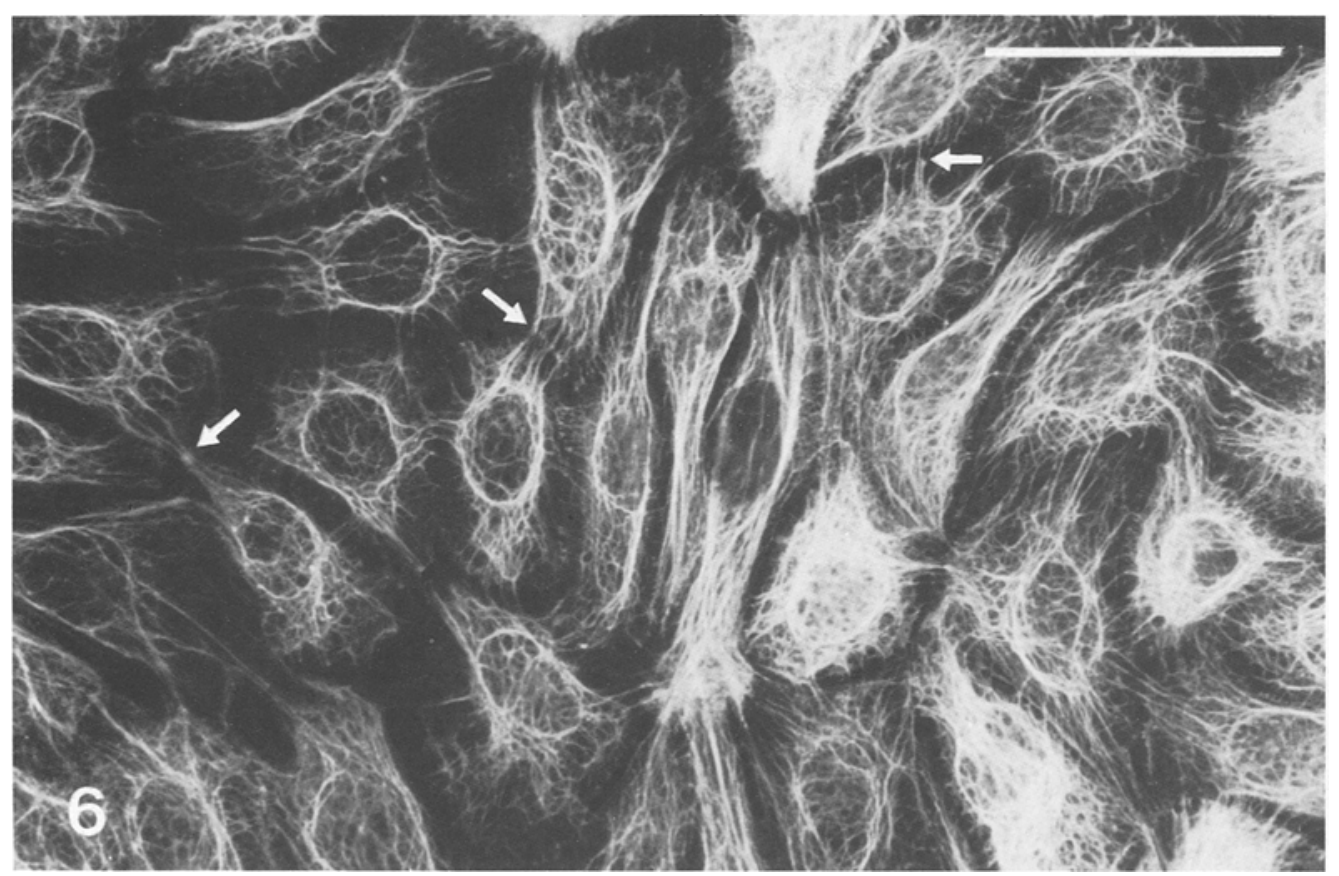

Fig. 6. Indirect immunofluorescence microscopy of an E-type colony after reaction with guinea pig antibodies to epidermal prekeratin. Note the fibril arrays extending throughout the whole cytoplasm. Arrows indicate desmosome-tonofibril complexes with typical fibril correspondence at cell-to-cell boundaries. Bar, $20 \mu \mathrm{m}$

majority of F-type colonies did not contain cells positive for this type of prekeratin. Only in four of the 10 densely growing $\mathrm{F}$ type colonies studied, a few isolated cells positive for prekeratin were detected. In AF/F- and AF-type colonies a variable fraction of cells (up to $30 \%$ in some cases and about $10 \%$ on average) showed the typical display of fibrils after staining with prekeratin antibodies (Fig. $7 \mathrm{a}$ ). Most but not all of these positively stained cells showed typical epithelial appearance in phase contrast microscopy, including cell-to-cell corresponences of positively stained fibrils at desmosomes (Fig. 7 a, b).

\section{Discussion}

In this study we have examined the types of intermediate-sized filaments present in cultured and non-cultured cells from amniotic fluid using indirect immunofluorescence microscopy. In addition, we have examined the character of these filaments in cells of frozen sections of the placenta and in isolated cells of the amniotic epithelium.

Our results show that cells from amniotic fluid as used in the diagnosis of prenatal disorders are heterogeneous with respect to their contents of intermediate-sized filaments. At least two major classes of cultured cells can be distinguished: (1) Cells containing filaments of the prekeratin-type are considered to be of epithelial origin and correspond to the E-type cells as classified by Hoehn et al. (1974). However, such cells positive for prekeratin filaments also occur in a scattered mode within colonies of the AF-type, thus demonstrating the heterogeneity of cells of AF-type colonies with respect to their origin. (2) Cells stained with antibodies to vimentin but not with antibodies to epidermal prekeratin may be of mesenchymal origin; they can appear in different morphologic forms, including typical F-type cells as well as certain pleomorphic cells present in AF-type colonies. The antibodies to prekeratin-like proteins used in this study have previously been shown to cross-react with proteins of the cytokeratin family of different species and of a large variety of tissues (Franke et al. 1981 b). Failure to decorate cells with these antibodies is therefore expected to indicate lack of prekeratin-like proteins rather than lack of cross-reactivity of prekeratin-like proteins in these cells. However, in view of the great diversity of cytokeratin polypeptides expressed in different tissues (Franke et al. $1981 \mathrm{~b}-\mathrm{e}$ ) we presently cannot exclude the possibility that these cells synthesize certain specific cytokeratins not recognized by the antibodies used.

The observation of both types of filaments, vimentin and prekeratin, in the epithelia-derived cells present in primary cultures of cells from amniotic fluids could be due to two reasons. The de novo formation of vimentin filaments during in vitro growth of epithelial cells has been shown for various cell types (Franke et al. 1978 a, 1979 d) and in particular detail for rat hepatocytes (Franke et al. to be published a). Our present data do not allow us to decide whether vimentin filaments occurring in cells of E-type colonies reflect the induction of vimentin synthesis during culture. On the other hand, the surprising finding of some positive reaction with both antibodies to vimentin and prekeratin using cryostat sections as well as isolated cells, on amniotic epithelial cells of human placenta but not on a variety of other epithelial cells of mammalian species, human included (Franke et al. 1979; Gabbiani et al. to be published), indicates that amniotic epithelial cells may be different from other epithelial cells in that they contain both types of filaments simultaneously already in situ. This possibility is currently being studied, employing also biochemical methods to identify the specific antigens recognized by the two antibodies in amniotic cells.

The exact tissues of origin of the specific classes of cells found in the amniotic fluid and cultures derived therefrom still remain to be clarified. Particularly pressing is the problem to distinguish between cells from fetal tissues and cells from the 

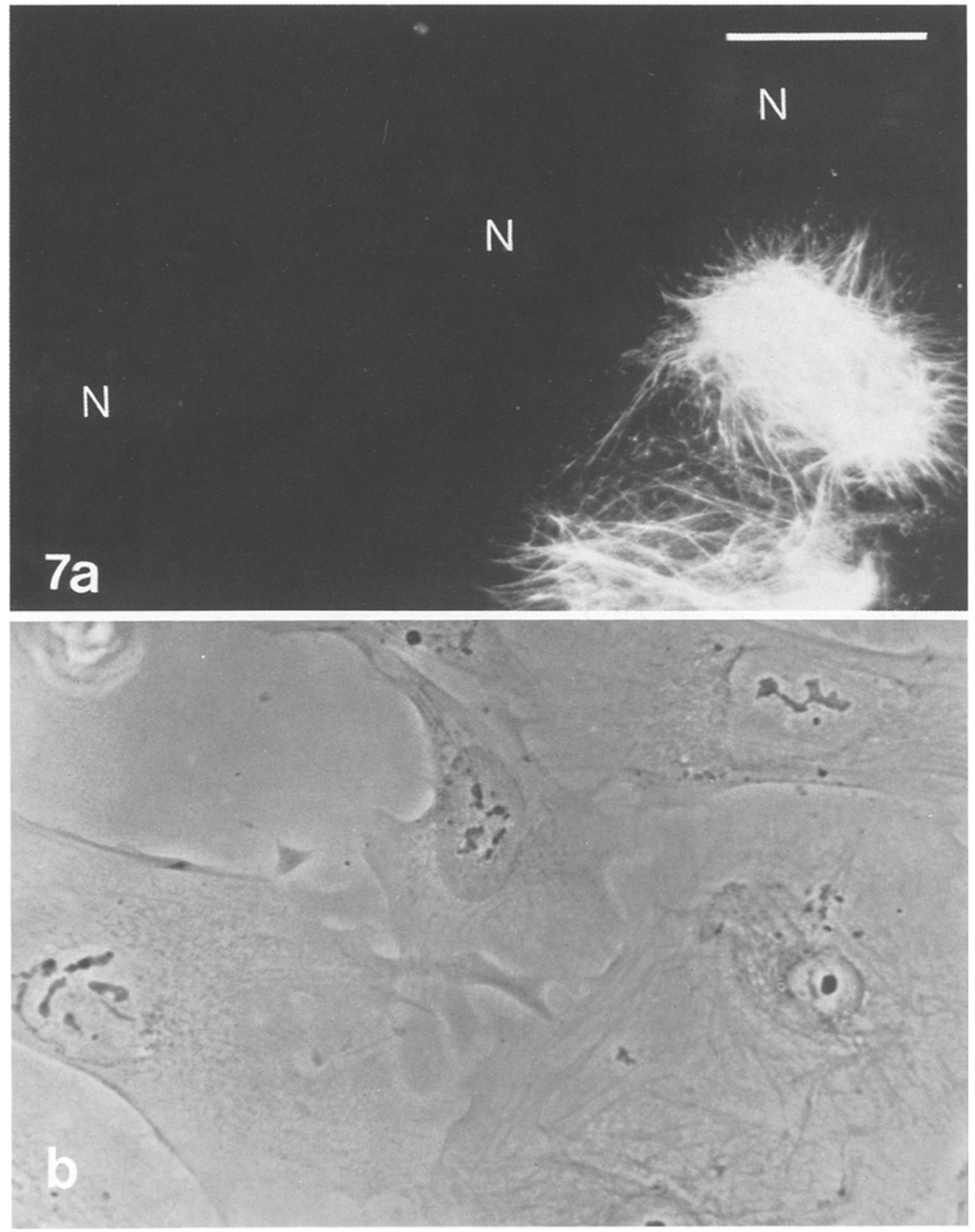

Fig. 7 a and b. AF-type colony seen after decoration with antibodies to epidermal prekeratin with epifluorescence optics (a) and with phase contrast optics (b). Two cells with an epithelial appearence show intensely stained fibrils, whereas the other cells do not show positive reaction. The nuclei of the unstained cells are denoted N. Bar, $20 \mu \mathrm{m}$

cytotrophoblast. Occasionally numerical chromosomal aberrations have been found in cultured amniotic fluid cells and in cells derived from the amniotic sac, while the fetus showed a normal chromosome complement (Hsu et al. 1976; Hsu 1981; Vekemans et al. 1981; our own unpublished observation). Detection of a chromosomal mosaic in cultured amniotic fluid cells therefore makes it necessary to prove the occurrence of the chromosomal abnormality in cells of known fetal origin before a decision of terminating a pregnancy can reasonably be done. Such a decision would be greatly facilitated if the fetal origin of certain clonable cells in the amniotic fluid could be proven and if culture conditions could be designed that would favor the proliferation of only the fetal cells. Correspondingly it would be important to have positive evidence for the specific tissue derivation of the epithelial components present in non-cultured and cultured amniotic fluids. It should be possible to answer the question whether such cells and colonies of cells have originated from amniotic epithelium or epidermis, or epithelia of the intestinal, respiratory, or urogenital tract, by taking advantage of recent observations of tissue-specificity of different polypeptides of the cytokeratin family in different epithelia (Franke et al. $1981 \mathrm{c}$ to be published b), utilizing biochemical microtechniques and/or monoclonal antibodies directed against these tissue-specific determinants in prekeratin-like molecules. 
Acknowledgements. The authors are indebted to Dr. W. Schmidt, Department of Obstetrics and Gynecology, University of Heidelberg, who carried out the amniocenteses, and to Drs. T. M. Schroeder and F. Vogel for continuous interest and support. We are especially grateful to Dr. M. Schachner for stimulating discussions and to E. Schmid for expert help in indirect immunofluorescence microscopy on isolated amniotic fluid cells. This work has been supported by the Deutsche Forschungsgemeinschaft. M.C. is a recipient of an "Ausbildungsstipendium" and T.C. of a "Habilitationsstipendium" of the Deutsche Forschungsgemeinschaft.

\section{References}

Alitalo K, Kurkinen M, Vaheri A, Krieg T, Timpl R (1980) Extracellular matrix components synthesized by human amniotic epithelial cells in culture. Cell 19:1053-1062

Aula P, Koskull H, Teramo K, Karjalainen O, Virtanen I, Lehto VP, Dahl D (1980) Glial origin of rapidly adhering amniotic fluid cells. Br Med J 281: 1456-1457

Bennett GS, Fellini S, Croop JM, Otto JJ, Bryan J, Holtzer H (1978) Differences among filaments subunits from different cell types. Proc Natl Acad Sci USA 75:4364-4368

Cremer M. Schachner M, Cremer T, Schmidt W, Voigtländer T (1981) Demonstration of astrocytes in cultured amniotic fluid cells of three cases with neural tube defect. Hum Genet $56: 365-370$

Crouch E, Bornstein P (1979) Characterization of a type IV procollagen synthesized by human amniotic fluid cells in culture. J Biol Chem 254:4197-4204

Franke WW, Schmid E, Osborn M, Weber K (1978 a) Different intermediate-sized filaments distinguished by immunofluorescence microscopy. Proc Natl Acad Sci USA 75:5034-5038

Franke WW, Weber K, Osborn M, Schmid E, Freudenstein C (1978 b) Antibody to prekeratin. Decoration to tonofilament arrays in various cells of epithelial character. Exp Cell Res 116:429-445

Franke WW, Appelhans B, Schmid E, Freudenstein C (1979a) The organization of cytokeratin filaments in the intestinal epithelium. Eur J Cell Biol 19:255-268

Franke WW, Appelhans B, Schmid E, Freudenstein C, Osborn M, Weber K (1979b) Identification and characterization of epithelial cells in mammalian tissues by immunofluorescence microscopy using antibodies to prekeratin. Differentiation 15:7-25

Franke WW, Schmid E, Weber K, Osborn M(1979 c) HeLa cells contain intermediate-sized filaments of the prekeratin type. Exp Cell Res 118:95-109

Franke WW, Schmid E, Winter S, Osborn M, Weber K (1979d) Widespread occurrence of intermediate-sized filaments of the vimentin type in cultured cells from diverse vertebrates. Exp Cell Res 123: $25-46$

Franke WW, Schmid E, Breitkreutz D, Lüder M, Boukamp P, Fusenig N, Osborn M, Weber K (1979e) Simultaneous expression of two different types of intermediate-sized filaments in mouse keratinocytes proliferating in vitro. Differentiation 14:35-50

Franke WW, Grund C, Schmid E (1979 f) Intermediate-sized filaments present in Sertoli cells are of the vimentin type. Eur J Cell Biol 19: $269-275$

Franke WW, Schmid E, Freudenstein C, Osborn M, Weber K (1981 a) Characterization and localization of cytokeratins by antibodies against purified prekeratin polypeptides in different epithelial cells. Front Matrix Biol 9:112-126

Franke WW, Denk H, Kalt R, Schmid E (1981 b) Biochemical and immunological identification of cytokeratin proteins present in hepatocytes of mammalian liver tissue. Exp Cell Res 131:299-318

Franke WW, Winter S, Grund C, Schmid E, Schiller DL, Jarasch ED (1981 c) Isolation and characterization of desmosome-associated tonofilaments from rat intestinal brush border. J Cell Biol 90: $116-127$

Franke WW, Mayer O, Schmid E, Denk H, Borenfreund E (to be published a) Differences of expression of cytoskeletal proteins in cultured rat hepatocytes and hepatoma cells. Exp Cell Res
Franke WW, Schiller DL, Moll R, Winter S, Schmid E, Engelbrecht J, Denk H, Krepler R, Platzer B (to be published b) Diversity of cytokeratins: Differentiation specific expression of cytokeratin polypeptides in epithelial cells and tissues. J Mol Biol

Gabbiani G, Kapanci Y, Barazzoni P, Franke WW (to be published) Immunochemical identification of intermediate-sized filaments in human neoplastic cells. A diagnostic aid for the surgical pathologist. Am J Pathol

Gerbie AB, Melancon SB, Ryan C, Nadler HL (1972) Cultivated epithelial-like cells and fibroblasts from the amniotic fluid: Their relationship to enzymatic and cytologic analysis. Am $\mathfrak{J}$ Obstet Gynecol 114:314-320

Hoehn H, Bryant EM, Karp LE, Martin GM (1974) Cultivated cells from diagnostic amniocentesis in second trimester pregnancies. I. Clonal morphology and growth potential. Pediatr Res 8:746-754

Hoehn H, Bryant EM, Fantel AG, Martin GM (1975) Cultivated cells from diagnostic amniocentesis in second trimester pregnancies. III. The fetal urine as a possible source of clonable cells. Hum Genet $29: 285-290$

Hsu LYF, Kim HJ, Hausknecht R, Hirschhorn K (1976) Prenatal diagnosis of $45, \mathrm{X} / 46, \mathrm{XY}$ mosaicism with postnatal confirmation in a phenotypically normal male infant. Clin Genet 10:232-238

Hsu LYF (1981) Fetoscopy and the preantal diagnosis of chromosomal mosaicism. N Engl J Med 304: 1176-1177

Hynes RO, Destree AT (1978) 10 nm filaments in normal and transformed cells. Cell 13:151-163

Hurych J, Macek M, Beniač F, Rezácová D (1976) Biochemical characteristics of collagen produced by long term cultivated amniotic fluid cells. Hum Genet 31:335-340

Jackson BW, Grund C, Schmid E, Bürki K, Franke WW, Illmensee K (1980) Formation of cytoskeletal elements during mouse embryogenesis. I. Intermediate filaments of the cytokeratin type and desmosomes in preimplantation embryos. Differentiation 17:161179

Jackson BW, Grund C, Winter S, Franke WW, Illmensee K (to be published) Formation of cytoskeletal elements during mouse embryogenesis. II. Epithelial differentiation and intermediate-sized filaments in early postimplantation embryos. Differentiation

Macek M, Hurych J, Rezácová D (1973) Collagen synthesis in long-term amniotic fluid cell cultures. Nature 243:289-290

Melancon SB, Lee SY, Nadler J (1971) Histidase activity in cultivated amniotic fluid cells. Science 173:627-628

Osborn M, Franke WW, Weber K (1977) Visualization of a system of filaments $7-10 \mathrm{~nm}$ thick in cultured cells of an epithelioid line (PtK2) by immunofluorescence microscopy. Proc Natl Acad Sci USA $74: 2490-2494$

Priest RE, Priest JH, Moinuddin JF, Keyser AJ (1977) Differentiation in human amniotic fluid cell cultures: I. Collagen production. J Med Genet 14:157-162

Ramaekers FCS, Osborn M, Schmid E, Weber K, Bloemendal H, Franke WW (1980) Identification of the cytoskeletal proteins in lensforming cells, a special epithelioid cell type. Exp Cell Res 127:309327

Schmid E, Tapscott S, Bennett GS, Croop J, Fellini SA, Holtzer H, Franke WW (1979) Differential location of different types of intermediate-sized filaments in various tissues of the chicken embryo. Differentiation 15:27-40

Schnitzer J, Franke WW, Schachner M (1981) Immunocytochemical demonstration of vimentin in astrocytes and ependymal cells of developing and adult mouse nervous system. J Cell Biol 90:435-447

Tyden O, Bergström S, Osborn M, Weber K (1981) Origin of amniotic fluid cells in mid-trimester pregnancies. Br J Obstet Gynaecol 88: $278-286$

Vekemans M, Perry TB, Hamilton E (1981) Chromosomal mosaicism on amniocentesis: an indication for fetoscopy? N Engl J Med 304: $52-53$

Received July 17 / Revised September 9, 1981 